\title{
Agroclimatic Indices of Rice (Oryza sativa L.) Influenced by Different Planting Times
}

\author{
A Sultana ${ }^{1}$, N Y Shaikh², M S Zahan², R Akter ${ }^{4}$, S A Islam5, M Issak ${ }^{6}$
}

\begin{abstract}
Meteorological variables have an important role in rice production. Considering this study was carried out in Aman season of 2016 at the research field of Bangladesh Rice Research Institute, Gazipur. The research was conducted in order to investigate the effects of planting time on various agrometeorological indices viz., accumulated growing degree days (GDD), heliothermal units (HTU), photo thermal units (PTU), and heat use efficiency (HUE) the yield of advanced/variety grown under different time of transplanting in the Gazipur climatic zone (AEZ, 28). The research was conducted as a split plot using randomized complete block design (RCBD) with three replications. In this research, three planting times $\left(1^{\text {st }}\right.$ Aug, $16^{\text {th }}$ Aug, and $31^{\text {th }}$ Aug) and the Advanced lines/varieties BR (Bio) 9786-BC2-119-1-1, BR (Bio) 9786-BC2-132-1-3 and BRRI dhan49 (check variety) were used in the experiment. The results showed that planting time significantly affected on grain yield. Among the genotypes, BR (Bio) 9786-BC2-119-1-1 and BR (Bio) 9786-BC2-132-1-3 produced significantly higher grain yield than check variety BRRI dhan49 in all the planting times. The variety (BRRI dhan49), transplanted at the first August, took maximum calendar days (136 days) to attain different phenological stages till physiological maturity coupled with highest growing degree days (2420 degree day) for maturity, lowest heat use efficiency $\left(2.25 \mathrm{~kg} \mathrm{ha}^{-1} \mathrm{c}^{-1}\right.$ day $\left.^{-1}\right)$, highest heliothermal units (15141.01 degree day hours) and lowest photothermal units (29678.81 degree day hours) resulting lower yield. Among the advanced lines the line BR (Bio) 9786-BC2-119-1-1 took higher calendar day (134 days) to attain different phenological stages till physiological maturity coupled with higher growing degree days (2393 degree day) for maturity, heat use efficiency ( $2.76 \mathrm{~kg}$ ha $^{-1} \mathrm{c}^{-1}$ day $\left.^{-1}\right)$, heliothermal units (13759.75 degree day hours) and photothermal units (30112.51 degree day hours) resulting higher yield. Taken together, the results indicate that the advanced line, BR (Bio) 9786-BC2-119-1-1, could be select as a best advanced line to release as a variety due to its higher grain yield.
\end{abstract}

Kew words: Rice, planting time, advanced lines/variety and agroclimatic indices

\section{INTRODUCTION}

In Bangladesh, traditionally, T. Aman occupied the largest rice harvested area. The broadcasting Aman is mostly planted in deeply flooded lowland areas. The transplanted Aman crops are grown mostly under rainfed conditions (FAO, 2002). Aman rice, is the monsoon-season rainfed rice which is the most widespread, including along the coastal areas. Two ways: direct seeding with Aus in March and April and transplantation between July and August is planted in Aman season. Both types are harvested from November through December (Shelley, 2016). Aman rice previously contributed a major portion of total rice, but Boro is now the major contributor to total rice production in the country, despite Aman coverage area being greater. Aus, Aman, and Boro rice were recently reported to account for $7 \%, 38 \%$, and $55 \%$, respectively, of the total rice production in Bangladesh (Risingbd, 2014). Total Aman rice covers 55, 90, 340 hectares land with a production of 1, 34, 83, 437 metric tons (BBS, 2015).

1Senior Scientific Officer, Agronomy Division, BRRI, 2Senior Scientific Officer, Biotechnology Division, BRRI, 3 Senior Scientific Officer, Agronomy Division, BRRI, 4 Scientific Officer, Agronomy Division, BRRI, 5Senior Scientific Officer, Agronomy Division, BRRI, Gazipur; ${ }^{6}$ Professor, Department of Soil Science, SAU, Dhaka $1207 .{ }^{*}$ Corresponding author's E-mail: amenasau@yahoo.com 
An increase in total rice production is required to feed the ever-increasing population of Bangladesh as the population growth rate of Bangladesh is 2 million per year, and if the population increases at this rate, the total population will reach 238 million by 2050 . On the other hand, the total cultivable land is decreasing at rate an alarming per year owing to the construction of industries, factories, houses, roads, and highways (Shelley, 2016).

Rice production is affected by various meteorological variables like rainfall, temperature etc. (Ji et al., 2007). Temperature is an important environmental factor that influences the growth, phenology and yield of crop (Bishnoi et al., 1995). The extreme agroclimatic conditions, particularly high temperature, reduce the plant growth and yield significantly (Satake and Yoshida, 1978). The crop growth response is mainly influenced by the microclimate of crop canopy. Temperature and light radiation are key factors affecting crop production. During crop growth period, the occurrence of various phenological events can be estimated by computing accumulated growing degree days (GDD) (Gouri et al., 2005). GDD provides an estimate of harvest date as well as development stages of crop (Ketring and Wheless, 1989). Thermal time can be used as a tool for characterizing thermal responses in different crops as it is an independent variable to describe plant development (Dwyer and Stewart, 1986). Heat use efficiency (HUE), i.e., efficiency of heat utilization in terms of dry matter accumulation, depends on genetic factors, crop type and sowing time and has great practical application (Rao et al., 1999). The duration of each phenophase determines the dry matter accumulation and its partitioning into different organs. Dalton, 1967; Wang, 1960 reported that the duration of growth stage of any particular species was directly related to temperature and it could be predicted using the sum of daily air temperature, it becomes imperative to have the knowledge of exact duration of various phenological stages of crop in a particular growing environment and their impact on its yield.

Before releasing a variety it is very important to determine optimum time of transplanting date to get higher yield. The promising lines have high yield potentials to be selected by planting rice seeding under varied planting dates in a particular season. Therefore, considering the above facts, the present study was conducted to determine the optimum transplanting time and yield with agroclimatic indices viz GDD, HUE, helio thermal units (HTU) and photothermal units (PTU) of T. Aman advanced rice lines to select best advanced line for release as variety.

\section{MATERIALS AND METHODS:}

The experiment was conducted at BRRI farm, Gazipur in T. Aman 2016 to find out optimum planting time and to select the best advanced line. Advanced lines were BR (Bio) 9786-BC2119-1-1 and BR (Bio) 9786-BC2-132-1-3 along with the check variety BRRI dhan49 (Table 1). Transplanting was started from 1 August to 31 August with 15 days intervals. Twenty-fiveday-old seedling was transplanted with $20 \mathrm{~cm}$ $\times 20 \mathrm{~cm}$ spacing and one seedling per hill. The experiment was laid down in spilt-plot design, where planting date was in the main plot and the advanced lines were in the sub-plot. Fertilizers were applied @76-12-52-12 kg ha-1 N-P-K-S respectively. All fertilizers were applied during final land preparation but urea was applied as top dress in three equal splits at 10, 30 and 45 DAT (day after transplanting). The soil at the study site is of fine silty clay loam type. The location previously had three season rice. The field was cleared and manually ploughed to provide a fine tilth for cultivation. Each plot was demarcated with a $40 \mathrm{~cm}$ walk way and a plot size of $3.2 \mathrm{~m} \times 2.2 \mathrm{~m}$. 
Table 1. Transplanting time with growth duration of three genotypes in T. Aman rice.

\begin{tabular}{lccc}
\hline & \multicolumn{3}{c}{ Growth duration } \\
\cline { 2 - 4 } Advanced line/varietiy & 1 Aug & Aug & Aug \\
\hline BR (Bio) 9786-BC2-119-1-1 & 134 & 131 & 130 \\
BR (Bio) 9786-BC2-132-1-3 & 133 & 134 & 132 \\
BRRI dhan49 (ck) & 136 & 135 & 130 \\
\hline
\end{tabular}

Weeds were manually controlled (2 times) 20 days after sowing and at maximum tillering stage. Also, Dursband was applied at $50 \mathrm{ml} / 16$ litres at panicle initiation stage to control stem borer infestation within the field. At harvest, the middle portion of each plot $\left(5 \mathrm{~m}^{2}\right)$ was harvested and the grain weight (grain yield was reported at $14 \%$ moisture) represent the plot after drying (Saito et al., 2006). The agroclimatic indices, namely, growing degreedays, heliothermal units and heliothermal use efficiency, photo-thermal units, and heat use efficiency were worked out. Weather data were collected from Physiology Division. BRRI, Gazipur.

\section{Growing degree days (GDD):}

Cumulative growing degree days were determined by summing the daily mean temperature above base temperature, expressed in degree day. This was determined by using the following formula as per (Nuttonson, 1995).

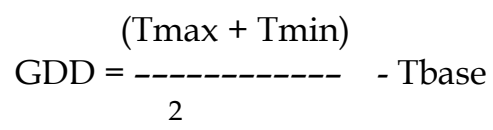

Where,

Tmax = Daily maximum temperature $\left({ }^{\circ} \mathrm{C}\right)$, Tmin $=$ Daily minimum temperature $\left({ }^{\circ} \mathrm{C}\right)$.

$\mathrm{T}$ base $=$ Minimum threshold/base temperature $\left({ }^{\circ} \mathrm{C}\right)$, A base temperature of $10^{\circ} \mathrm{C}$ was used for rice basis as per (Gao, 1992).

\section{Heat use efficiency (HUE):}

Heat use efficiency (HUE) = Grain yield (kg/ha)/GDD

\section{Helio-thermal units (HTU):}

The product of GDD and corresponding actual sunshine hours for that day were computed on daily basis as per (Satake, 1978).

$\mathrm{HTU}=\mathrm{GDD} \times$ Actual sunshine hours

\section{Photothermal units (PTU) :}

The product of GDD and corresponding day length for that day were computed on daily basis as follows as per (Gouri, 2005).

$\mathrm{PTU}=\mathrm{GDD} \times$ Day length

Day length refers to maximum possible sunshine hours.

Growing degree-days, heat use efficiency, heliothermal units and photothermal units were accumulated from the date of planting to each phenological stage and accumulated from transplanting to physiological maturity.

\section{RESULTS AND DISCUSSION}

\section{Grain yield}

Rice grain yield is depends on total number of panicles, number of grains per panicle and thousand grain weight, which was significantly influenced by the time of planting (Table 2). First planting time (1 Aug) produced the maximum grain yield in all the genotypes compare to the second (16 Aug) and third (31 Aug) planting time (Table 2). The reason can be attributed to the suitable growth duration, coincidence of the phenological stages, especially the heading and grain filling stages with day length and more favorable temperature. Positive influence of temperature on dynamic formation of the grain yield components resulting higher dry matter accumulation capacity. The minimum grain yield was found in all the genotypes at $3^{\text {rd }}$ planting time. Grain yield decreased in the $3^{\text {rd }}$ planting time due to the reduction in yield attributing characteristics with delay transplanting and excessive heat during the pollination period and grain filling stage 
caused disorder in grain formation and grain weight which reduced the grain yield. The results were in accordance with the findings of (Sharma et al. 2011), Noorbakhshian (2003), Pirdashti et al. (2003) and Gines et al. (1987). There was a significant difference among the genotype and variety in terms of grain yield (Table 2). The highest grain yield $\left(6630 \mathrm{~kg} \mathrm{ha}^{-1}\right)$ was obtained in the BR (Bio) 9786-BC2-119-1-1 genotype and followed by $6020 \mathrm{~kg} \mathrm{ha}^{-1}$ in the BR (Bio) 9786-BC2-132-1-3 genotype. The lowest grain yield (5450 kg ha-1) was observed in the check variety, BRRI dhan49. This disparity was caused by the difference between genotypes in terms of the growth period duration, panicle emergence time, fertility rate, the number of grains per panicle, the 1000 grains weight, and heat-sensitivity level (Table 2). The results were similar with the findings of Kawakata and Yajima (1995) and Yoshida (1978) who reported that a determining role for temperature and day duration on panicle emergence and their impacts on physiological, growth and maturity processes resulting higher grain yield. The interaction effect of transplanting time and genotypes significantly differ on grain yield (Table 3). Reduction of grain yield due to delayed planting was to an extent of $1.5 \%$ and $6.33 \%$ in crop planting during second (16 August) and third (31 August) planting time respectively, compared to the first (1 August) planting time (Table 3).

Table 2. Interactive effect of planting time on yield $(\mathrm{Kg} / \mathrm{ha})$ of advanced lines/varieties in T. Aman rice.

\begin{tabular}{lccc}
\hline Advanced lines/varieties & \multicolumn{3}{c}{ Yield (kg ha) } \\
\cline { 2 - 4 } & 1 Aug & 16 Aug & 31 Aug \\
\hline BR (Bio) 9786-BC2-119-1-1 & 6630 & 6400 & 6000 \\
BR (Bio) 9786-BC2-132-1-3 & 6020 & 6000 & 5570 \\
BRRI dhan49 (ck) & 5450 & 5440 & 5080 \\
CV\% & & 2.86 & \\
Lsd (0.05) for transplant time & & 0.12 & \\
Lsd (0.05) for variety & & 0.14 \\
Lsd (0.05) for transplant time* variety & & 0.26 \\
\hline
\end{tabular}

Table 3. Extent of reduction in yield of genotypes due to delay in planting time.

\begin{tabular}{lcc}
\hline Advanced lines/varieties & Reduction in grain yield (kg/ha) & 31 Aug \\
\cline { 2 - 3 } & 16 Aug & $6 \%$ \\
BR (Bio) 9786-BC2-119-1-1 & $4 \%$ & $7 \%$ \\
BR (Bio) 9786-BC2-132-1-3 & $0.33 \%$ & $6 \%$ \\
BRRI dhan49 (ck) & $0.18 \%$ & 6 \\
\hline
\end{tabular}

Table 4. Growing degree days requirement of genotypes under different planting times.

\begin{tabular}{lccc}
\hline & \multicolumn{3}{c}{ GDD (Growing degree days) } \\
\hline Advanced line/variety & 1 Aug & 16 Aug & 31 Aug \\
\hline BR (Bio) 9786-BC2-119-1-1 & 2399 & 2234 & 2088 \\
BR (Bio) 9786-BC2-132-1-3 & 2388 & 2272 & 2109 \\
BRRI dhan49 (ck) & 2420 & 2283 & 2088 \\
\hline
\end{tabular}

90 Sultana et al 
Table 5. Heat use efficiency (HUE) requirement of genotypes under different planting times.

\begin{tabular}{lccc}
\hline & \multicolumn{3}{c}{ Heat use efficiency ( HUE) } \\
\cline { 2 - 4 } Genotype & 1 Aug & 16 Aug & 31 Aug \\
\hline BR (Bio) 9786-BC2-119-1-1 & 2.76 & 2.86 & 2.87 \\
BR (Bio) 9786-BC2-132-1-3 & 2.52 & 2.64 & 2.64 \\
BRRI dhan49 (ck) & 2.25 & 2.38 & 2.43 \\
\hline
\end{tabular}

Table 6. Heliothermal units (HTU) requirement of genotypes under different planting times.

\begin{tabular}{lccc}
\hline & \multicolumn{3}{c}{ Helio-thermal units (HTU) } \\
\cline { 2 - 4 } Advanced line/variety & 1 Aug & 16 Aug & 31 Aug \\
\hline BR (Bio) 9786-BC2-119-1-1 & 13759.75 & 11467.93 & 1052.026 \\
BR (Bio) 9786-BC2-132-1-3 & 13712.14 & 11636.24 & 10663.14 \\
BRRI dhan49 (ck) & 15141.01 & 11467.93 & 10743.62 \\
\hline
\end{tabular}

Table 7. Yield response of genotypes to heliothermal units and heliothermal use efficiency across planting time and genotypes.

\begin{tabular}{lccc}
\hline & & Time of planting & 31 Aug \\
\cline { 2 - 4 } & 1 Aug & 16 Aug & 6000 \\
\hline Genotypes & & & 10520.26 \\
BR (Bio) 9786-BC2-119-1-1 & 6630 & 6400 & 0.57 \\
Yield (Kg/ha) & 13759.75 & 11467.93 & 31 Aug \\
HTU & 0.48 & 0.55 & 5570 \\
HTUE (kg/HTU) & & & 10663.1 \\
Genotype & 1 Aug & 16 Aug \\
BR (Bio) 9786-BC2-132-1-3 & 6020 & 6000 & 0.50 \\
Yield (kg/ha) & 13712.14 & 11636.24 & 0.51 \\
HTU & 0.43 & & 31 Aug \\
HTUE (kg/ HTU) & & 16 Aug & 5080 \\
Genotype & 1 Aug & 5440 & 10743.62 \\
BRRI dhan49 (ck) & 5450 & 11467.93 & 0.47 \\
Yield (kg/ha) & 15141.01 & 0.47 & \\
HTU & 0.35 & & \\
HTUE (kg/ HTU) & & & \\
\hline
\end{tabular}

Table 8. Photothermal units (PTU) requirement of genotypes under different planting times.

\begin{tabular}{lccc}
\hline & \multicolumn{3}{c}{ Photo-thermal unit (PTU) } \\
\cline { 2 - 3 } Advanced lines/varieties & 1 Aug & 16 Aug & 31 Aug \\
\hline BR (Bio) 9786-BC2-119-1-1 & 30112.51 & 25653.48 & 23359.90 \\
BR (Bio) 9786-BC2-132-1-3 & 30060.07 & 26044.92 & 23579.26 \\
BRRI dhan49 (ck) & 29678.81 & 26156.42 & 23359.90 \\
\hline
\end{tabular}

Agroclimatic Indices of Rice (Oryza sativa L.) Influenced by Different Planting Times 91 


\section{Growing degree days}

Table 4 presents accumulation of growing degree days (GDD) were calculated at different planting times of the advanced lines/varieties during crop seasons. The higher number of GDD was accumulated by the first (1 August) planting time followed by second (16 August) and third (31 August) transplanting time in all of the advanced lines/varieties. Among the advanced lines/varieties, the higher GDD (2420 degree $\mathrm{C} /$ day) was recorded in the variety BRRI dhan49 followed by the BR (Bio) 9786-BC2119-1-1 (2399 degree C/day) at first transplanting time. Growing degree days (GDD) were decreased with late transplanting for all the advanced lines/varieties during the crop season. In general, earlier transplanting time crop availed higher degree days and with each delay in transplanting the degree day consumption decreased during the crop seasons. It is reported that GDD accumulation is higher under early transplanting. Reduction in heat units with delay in transplanting has been reported by Singh and Pal (2003), Rajput et al. (1987) and Abhilash et al. (2017). Khan et al. (2006) found that the GDD requirement for the maturity was the highest in Lal Swarna (2385 degree C/day), followed by IR-36 (1975 degree C/day) and Kshitish (1913 degree C/day).

\section{Heat use efficiency}

Total heat energy available to any crop is never completely converted to dry matter even under most favorable agro climatic conditions (Table 5). Heat use efficiency (HUT) was calculated at various time of transplanting of the used advanced lines/varieties and is presented in Table 5. HUE was increased with delay the transplanting time. Among the transplanting time, $31^{\text {st }}$ August transplanted crop exhibited maximum HUE followed by $16^{\text {th }}$ August and $1^{\text {st }}$ August transplanting during the crop season for all the advanced lines/variety. Among the three advanced line/varity, BR (Bio) 9786-BC2-119-1-1 was recorded maximum HUE $\left(2.87-2.76 \mathrm{~kg} \mathrm{ha}^{-1}{ }^{\circ} \mathrm{C}^{-1}\right.$ day $\left.^{-1}\right)$. The second highest HUE (2.64-2.52 kg $\mathrm{ha}^{-1}{ }^{\circ} \mathrm{C}^{-1} \mathrm{day}^{-1}$ ) was found in the advanced line, BR (Bio) 9786-BC2-132-1-3. The lowest HUE (2.43-2.25 kg ha-1 $\left.{ }^{\circ} \mathrm{C}^{-1} \mathrm{day}^{-1}\right)$ was recorded in BRRI dhan49.

\section{Heliothermal units}

Table 6 presents heliothermal units (HTU) that are required for attaining different transplanting times of the advanced lines/varieties during the crop seasons. It was observed that HTU accumulation increased in all the advanced lines/variety transplanted at first (1st $)$ August and HTU accumulation decreased with delay the transplanting time in all the advanced lines/variety. Maximum heliothermal units were calculated in the advanced lines/variety transplanted on $1^{\text {st }}$ August followed by the lines/variety transplanted on $16^{\text {th }}$ August and 31 ${ }^{\text {st }}$ August, respectively. The maximum helio-thermal units $\left(15141.01^{\circ} \mathrm{C}\right.$ day hour) were recorded in the BRRI dhan 49 followed by $\left(13759.75^{\circ} \mathrm{C}\right.$ day hour) in the advanced line BR (Bio) 9786-BC2$119-1-1$ and the lowest $\left(10520.26^{\circ} \mathrm{C}\right.$ day hour) in the advanced line BR (Bio) 9786-BC2-119-1-3 at the first transplanting time ( $1^{\text {st }}$ August). These findings are similar with Kaur and Dhaliwal (2014) who reported that heliothermal units was maximum in crop that are transplanted on $15^{\text {th }}$ June as compared to the transplanting time $30^{\text {th }}$ June and $15^{\text {th }}$ July.

\section{Heliothermal use efficiency}

Table 6 presents heliothermal use efficiency was recorded by the different planting times and advanced lines/variety of rice. At the first planting time, the advanced line BR (Bio) 9786BC2-119-1-1 has exhibited high HTUE than the advanced line BR (Bio) 9786-BC2-119-1-3 and BRRI dhan49. Similar trend of HTUE were also found in the second (16 th August) and third (31 th August) planting time. This could be due to exposure of long duration genotype to 
bright sunny days combined with long dry spells at their later growth period (grain filling stage). In all, early planting rice has taken the advantage of optimum temperature and sunlight during the early stage of plant development and thereby avoided adverse situations during its life cycle.

\section{Photothermal units}

The data on variation of photothermal units (PTU) with respect to the transplanting time and advanced lines/varieties were observed. The PTU was higher in the first transplanting time ( $1^{\text {st }}$ August) followed by second transplanting time (16 ${ }^{\text {th }}$ August) and then third planting time (31 August) in all the advanced lines/varieties (Table 7). Among the advanced lines/varieties, higher PTU was recorded in advanced line for BR (Bio) 9786-BC2-119-1-1 (30112.51 ${ }^{\circ} \mathrm{C}$ day hour) followed by BRRI dhan49 $\left(29678.81^{\circ} \mathrm{C}\right.$ day hour) at the first transplanting time ( $1^{\text {st }}$ August). PTU decreased in late transplanting for all advanced lines/varieties (Table 7). Earlier transplanted rice accumulated higher photothermal units for all the advanced lines/varieties and with delay in transplanting time, PTU requirements decreased (Table 8).

\section{CONCLUTION}

Taken together, it may be concluded that maximum grain yield can be obtained from the advanced line BR (Bio) 9786-BC2-119-1-1 and BR (Bio) $9786-B C 2-132-1-3$ by using the $1^{\text {st }}$ planting time (1st August). Our result indicates that the different agroclimate indices viz. GDD, HTU, and PTU were higher in the advanced line/verity of rice transplanted at $1^{\text {st }}$ August that would be the positive yield regulator of rice. It provides a scientific basis for determining higher yield that could be the effect of temperature, radiation or photoperiod on phenological behavior of a standing crop.

\section{REFERENCES}

Abhilash, D C S, R Singh, Premdeep, R Sharma. 2017. Agrometeorological indices and phenology of Basmati Rice (Oryza sativa L.) under different dates of transplanting. International Journal of Current Microbiology and Applied Science 6(3):212-222.

BBS (Bangladesh Bureau of Statistics). 2015. Estimation of Aman Rice (Husked), 2015-2016, at the website: www.bbs.gov.bd. BRKB 2011 (Bangladesh Rice Knowledge Bank), BRRI, Gazipur. Agriculture Research Journal 6: 35-38.

Bishnoi, O P, S Singh and R Niwas. 1995. Effect of temperature on phonological development of wheat (Triticum aestivum L.) crop in different row orientations. Indian Journal Agricultural Science 65: 211-14.

Dalton, L G. 1967. A positive response of yield on maturity of Sorghum. Crop Sciences 7: 721-26.

Dwyer, L M and D W Stewart. 1986. Leaf area development in field grown maize. Agronomical Journal 78: 334-48.

FAO 2002. FAO Rice Information, Volume 3, December 2002. Food and Agriculture Organization of the United Nations, Rome, Italy.

Gao, L and Z Jin. 1992. Rice clock model: a computer model to simulate rice development, Agricultural and Forest Meteorology 60 (1-2): 1-16.

Gines, H G, M M Tamisin, R A Morris and P Garrity. 1987. Weather factors limiting wet-dry transition period rice yield in a partially irrigated environment in central Luzon Philippines. Philippinean Journal of crop science supplement 12: 32-48.

Gouri, V, Reddy, D R, Rao, S B S N and A Y Rao. 2005. Thermal requirement of Rabi groundnut in southern Telangana zone of Andhra Pradesh. Journal Agrometeorology 7(1): 90-94.

Ji, B, Y Sun, S Yang and J Wan. 2007. Artificial neutral networks for rice yield prediction in mountainous regions, Journal of Agricultural Science 145(3): 24961.

Kaur, A and L K Dhaliwal. 2014. Agroclimatic indices of rice (Oryza sativa L.) under different dates of planting. Progressive Research 9 (1): 222-227.

Kawakata, T and M Yajima. 1995. Modelling flowering time of rice plants under natural photoperiod and constant air temperature. Agronomy Journal 50: 393-396.

Ketring, D L and T G Wheless. 1989. Thermal requirement for phenological development of peanut. Agronomy Journal 8 (16): 910-17.

Kumar and Jha. 2000. Constraints to the adoption of modern varieties of rice in Bihar, Eastern India. In Characteristics and understanding rainfed environment (Eds. Tuong et al.). IRRI, Philippines, pp. 305-321. 
Khan, TN, A Razzaq, M shahbaz, S Ajmal, GM Ali and MF Joyia. 2006. Performance of four varieties of fine rice for best yield and yield components under climate conditions of Bahawalpur (Pakistan). J. agril. Soc. Sci. 2 (3): 187-188.

Noorbakhshian, S J. 2003. Effect of seed rate, planting date in nursery and transplanting date on yield and yield components of rice. Iranian Journal of Crop Sciences, 5(4): 261-272 (in Persian).

Nuttonson, M Y. 1995. Wheat climate relationship and use phenology in ascertaining the thermal and photothermal requirement of wheat. American Institute of Crop Ecology, Washington DC, pp. 338.

Pirdashti, H, Z T Sarvestani and M Nasiri. 2003. Study on dry matter and nitrogen remobilization rice (Oryza sativa L.) genotypes under different transplanting dates. Iranian Journal of Crop Science, 5: 46-55. (in persian).

Rajput, R P, M R Deshmukh and V K Paradkar. 1987. Accumulated heat unit and phenology relationships in wheat (TriticumaestivumL.) as influenced by planting dates under late sown conditions. Journal of Agricultural Crop Science 159: 345-48.

Rajput, R P, D Gao, L. and Z Jin. 1992. Rice clock model: a computermodel to simulate rice development, Agricultural and Forest Meteorology, 60(1-2) : 116.
Rao, V U M, D Singh and R Singh. 1999. Heat use efficiency of winter crops in Haryana. Journal of Agrometeorology1(2):143-8.

Risingbd. 2014. www.risingbd.com/english/Rice_ production reaches 34449 million ton in FY_2013$14 / 16217$.

Shelley, I J, M T Nosaka, M K Nakata, M S Haque and Y Inukai. 2016. Rice Cultivation in Bangladesh: Present Scenario, Problems, and Prospects, Journal of International Cooperation Agricultural Development 14: 20-29.

Singh, S and M Pal. 2003. Growth, yield and phonological response of wheat cultivars to delayed sowing. Indian Journal of Plant Physiology 8: 277-86.

Satake, T and S Yoshida. 1978. High temperature sterility in Indica rice at flowering, Journal of Crop Science 47: 6-17.

Thavaprakash, $\mathrm{N}$ and R Jagannathan. Velayudham and L Gurusamy. 2007. Seasonal influence on phenology and accumulated heat units in relation to yield of baby corn. International Journal of Agricultural Research. 2 (9): 826-831.

Wang, J Y. 1960. A critique of the heat unit approach to plant response studies. Ecology 41: 785-90.

Yoshida, S. 1978. Tropical climate and its influence on rice IRRI Research Paper Serial 20. 